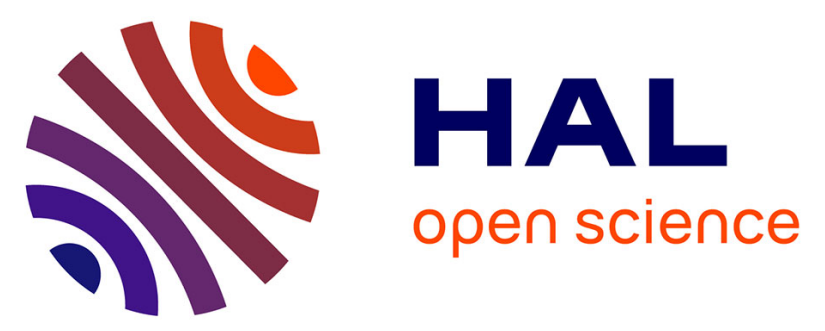

\title{
NON-LINEAR OBSERVER-BASED CONTROL OF FLEXIBLE-JOINT MANIPULATORS USED IN MACHINE PROCESSING
}

\author{
Jinna Qin, François Leonard, Gabriel Abba
}

\section{- To cite this version:}

Jinna Qin, François Leonard, Gabriel Abba. NON-LINEAR OBSERVER-BASED CONTROL OF FLEXIBLE-JOINT MANIPULATORS USED IN MACHINE PROCESSING. ASME 2012 11th Biennial Conference on Engineering Systems Design and Analysis, ESDA 2012; Nantes, Jul 2012, France. pp.251-260, 10.1115/ESDA2012-82048 . hal-00998950

\section{HAL Id: hal-00998950 https://hal.science/hal-00998950}

Submitted on 3 Jul 2014

HAL is a multi-disciplinary open access archive for the deposit and dissemination of scientific research documents, whether they are published or not. The documents may come from teaching and research institutions in France or abroad, or from public or private research centers.
L'archive ouverte pluridisciplinaire HAL, est destinée au dépôt et à la diffusion de documents scientifiques de niveau recherche, publiés ou non, émanant des établissements d'enseignement et de recherche français ou étrangers, des laboratoires publics ou privés. 


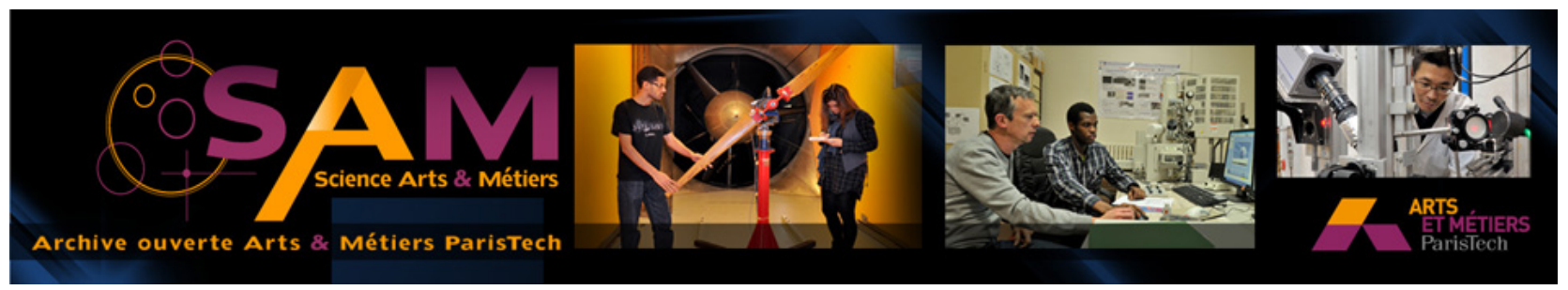

Science Arts \& Métiers (SAM)

is an open access repository that collects the work of Arts et Métiers ParisTech researchers and makes it freely available over the web where possible.

This is an author-deposited version published in: http://sam.ensam.eu Handle ID: .http://hdl.handle.net/10985/8217

\section{To cite this version :}

Jinna QIN, François LEONARD, Gabriel ABBA - NON-LINEAR OBSERVER-BASED CONTROL OF FLEXIBLE-JOINT MANIPULATORS USED IN MACHINE PROCESSING - 2012 


\section{NON-LINEAR OBSERVER-BASED CONTROL OF FLEXIBLE-JOINT MANIPULATORS USED IN MACHINE PROCESSING *}

\author{
Jinna Qin ${ }^{\dagger}$ \\ Design, Manufacturing Engineering \\ and Control Lab. \\ Arts et Métiers ParisTech \\ ENSAM, 4 rue Augustin Fresnel \\ 57078, Metz, France \\ Email: jinna.qin@ensam.eu
}

\author{
François Léonard \\ Design, Manufacturing Engineering \\ and Control Lab. \\ Arts et Métiers ParisTech \\ ENIM, 1 route d'Ars Laquenexy \\ 57070, Metz, France \\ Email: leonard@enim.fr
}

\author{
Gabriel Abba \\ Design, Manufacturing Engineering \\ and Control Lab. \\ Arts et Métiers ParisTech \\ ENSAM, 4 rue Augustin Fresnel \\ 57078, Metz, France \\ Email: gabriel.abba@ensam.eu
}

\begin{abstract}
This paper proposes to use a non-linear observer to build the state and the external force of flexible manipulator robots during their machining (composite materials) processes or Friction Stir Welding (FSW) processes. These two different processes have a problem in common: the flexibility of the robot can not be neglected, that is to say, the errors due to the deformation of the links should be taken into account. However, in most industrial robots, the real positions and velocities of each link are not measured, so in this study, an observer is proposed to reconstruct the real angular positions and velocities of links by using the measured angular positions and the velocities of actuators. A simulation by Matlab/Simulink has been carried out with a 2 axis Robot during its machining processes: the proposed observer showed great performances in estimating the state of the robot (position and velocity). Then, in order to improve the tracking accuracy in the tool frame, the state of the external force along the forward direction ( $x$ ) and its normal direction ( $y$ ) are required, while they are also not measured by our robot. A disturbance observer has been added to reconstruct the processing force. A good precision during the proposed processes have been obtained using the latter. This study contributes to solve the problem from the point of
\end{abstract}

\footnotetext{
*THIS WORK IS SUPPORTED BY FRENCH NATIONAL RESEARCH AGENCY UNDER THE PROJECT NUMBER ANR-2010-SEGI-003-01COROUSSO

${ }^{\dagger}$ Address all correspondence to this author
}

view of accuracies during the machining processes.

\section{INTRODUCTION}

Manufacturing processes such as machining and welding are widely applied in production industry. This study focus on two special processes: machining of composite materials and the Friction Stir Welding (FSW) process. These two applications have an innovative character: the first one concerns an application of composite materials, and the second one is a new development of welding. Composite materials are used extensively for their high specific properties of strength and stiffness, however, these materials are difficult to machine due to nonhomogeneous, anisotropic and reinforced by very abrasive components. The FSW is a solid state welding technology that can be used for many joining applications. The process uses a nonconsumable rotation tool consisting of a pin extending below a shoulder, plunges into the work piece such that both the pin and the shoulder are in contact with the piece $[1,2]$. The technical and economic performances of some manufacturing processes can be greatly improved by using a manipulator or a robotic system as holder of the production tooling. However, using robot to do these two processes is a challenge: the natural rigidities of industrial robots are not sufficient to perform the tasks in the requirements of the processes. Actually, those processes are carried out by some special developed machines which need a great 
investment. In the sector of aeronautic industry, these two processes need to be strongly applied. New technologies are demand to reduce the investment and to improve the quality of the products. Due to a strong external force during the operations, the deformations of the robot cannot be neglected, therefore, the real angular positions and velocities of links are different from those determined by the geometric model of the robot. Moreover, to make an accurate machining or welding, the forces exerted on the material should be measured. Unfortunately, most of the industrial robots have only motor side measurements, thus a new approach to estimate link side states as well as the external force is required. Nevertheless, in case of welding, a force sensor is added to get at least the axial effort to the work plan, but the path effort $F_{x}$ and normal effort $F_{y}$ are still unknown.

There are many control methods available for the flexible robots [3] such as iterative learning control, adaptive control, backstepping, sliding mode control, neural networks, singular perturbations, composite control, pole placement, input shaping, passivity-based control, robustification by Lyapunov's second method, model-based feedforward control [4]. A good description of these control methods can be found in [5-8].

Disturbance observer technique is widely used in mechanical servo systems and observers are often used for the state estimations $[9,10]$. An adaptive robust control of FSW and an observer-based adaptive robust control (ARC) approach is discussed in [11] where it is proved that the axial force can be also estimated by an observer. An application of disturbance observers to nonlinear systems is reported in [12]. An accelerationbased state observer is presented in [13]. Subrahmanya and Shin [14] propose a method of state estimation. There are a lot of observer methods proposed by other researchers such as highgain observers, sliding mode observers [15], extended state observers, Kalman Filter and the Luenberger observer. In order to realize these operations, we propose an improved observer which can estimate not only the unmeasured states but also the external force.

This paper is organized as follows: a simplified model of flexible manipulators and the model of processing force for the two processes that mentioned above will be presented in the first part. The second part proposes a new observer which uses motor side measurements to reconstruct the state of robot as well as the external force. In the third part, a simulation is carried out by Matlab/Simulink to verify the tracking performance with the proposed observer. And finally, a conclusion and some further applications of this study will be presented.

\section{MODELING OF ROBOT AND PROCESSES}

Robotic manipulators are highly nonlinear and coupled dynamic systems, there also subjected to different external disturbances. This study is a part of the project COROUSSO (see acknowledgment). The objective of this project is to realize ma-
TABLE 1. Model parameters of the robot IBM7545.

\begin{tabular}{|c|c|c|}
\hline Name & Description (unit) & Value \\
\hline$l_{1}, l_{2}$ & length of link (m) & $0.40 ; 0.25$ \\
\hline$m_{1}, m_{2}$ & mass of link ( $\mathrm{kg})$ & $12.70 ; 4.35$ \\
\hline$m_{l}$ & mass of the spindle $(\mathrm{kg})$ & 1.34 \\
\hline$N_{1}, N_{2}$ & gear transmission factor & $157 ; 80$ \\
\hline$K_{1}, K_{2}$ & elasticity constante $\left(\mathrm{N} \mathrm{m}^{-1}\right)$ & $\begin{array}{l}3.6710^{4} \\
8.9010^{3}\end{array}$ \\
\hline$r_{1}, r_{2}$ & $\begin{array}{l}\text { distance between axis } \\
\text { and center of gravity (m) }\end{array}$ & $\begin{array}{l}0.153 \\
0.084\end{array}$ \\
\hline$K_{e 1}, K_{e 2}$ & $\begin{array}{l}\text { motor torque constant } \\
\left(\mathrm{Nm} \mathrm{V}^{-1}\right)\end{array}$ & $\begin{array}{l}0.1099 \\
8.9010^{3}\end{array}$ \\
\hline$J_{m 1}, J_{m 2}$ & motor inertia $\left(\mathrm{kg} \mathrm{m}^{2}\right)$ & $\begin{array}{l}1.5010^{-4} \\
0.0496\end{array}$ \\
\hline$f_{m 1}, f_{m 2}$ & $\begin{array}{l}\text { coefficients of viscous friction } \\
\text { on the motor side }\left(\mathrm{Nm} \mathrm{s} \mathrm{rad}{ }^{-1}\right)\end{array}$ & $\begin{array}{l}7.1810^{-5} \\
2.5810^{-5}\end{array}$ \\
\hline$f_{q 1}, f_{q 2}$ & $\begin{array}{l}\text { viscous friction of the joints } \\
(\mathrm{Nm} \mathrm{s} \mathrm{rad}-1)\end{array}$ & $10 ; 10$ \\
\hline
\end{tabular}

chining process and FSW process with industrial robots. In a first step, in order to simplify the approach, the tool is considered to stay in a horizontal plan during the machining process, the considered robot is a Scara robot which has two joint axis in parallel. The necessary parameters are taken from a robot IBM7545 that presents in [16]. It is a robot not well adapted to this task, but we will study firstly the problems addressed.

Hereafter, the flexibility of joints, the efforts applied by the robot, the gravity and the frictions are taken into account.

\section{A. Model of two axis flexible joint robot}

The model parameters of two-link flexible manipulator used in the simulations are given in Table 1. It is supposed that the tool is fixed at the end of the second axis and its rotation axis is assumed perpendicular to the work plan $(x, y)$, and the tool moves only in the plan (see Figure 1). Assuming that the links are rigid and only the joints have torsional stiffness due to the gearbox that are taken into account.

The position of the tool $\left(x_{2}, y_{2}\right)$ is calculated with the articular positions of each link $q=\left[\begin{array}{ll}q_{1} & q_{2}\end{array}\right]^{T}$ by using the geometric model:

$$
\left\{\begin{array}{c}
x_{2}=l_{1} \cos \left(q_{1}\right)+l_{2} \cos \left(q_{1}+q_{2}\right) \\
y_{2}=l_{1} \sin \left(q_{1}\right)+l_{2} \sin \left(q_{1}+q_{2}\right)
\end{array}\right.
$$




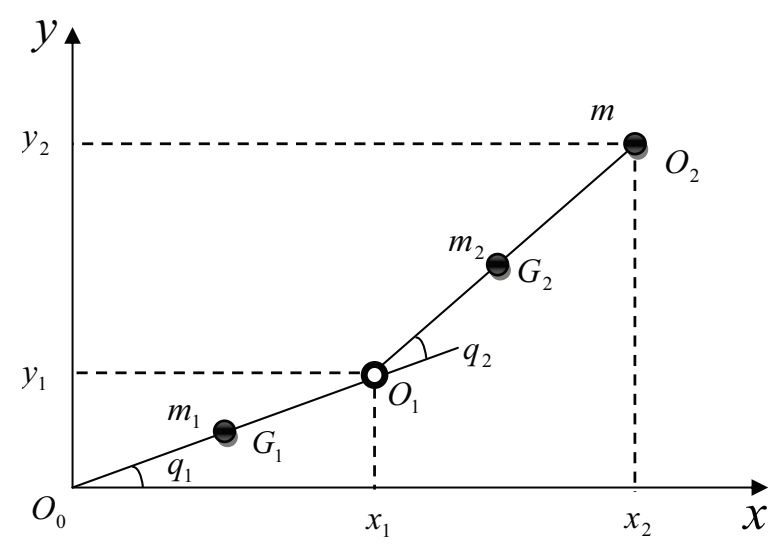

FIGURE 1. Geometric model of robot

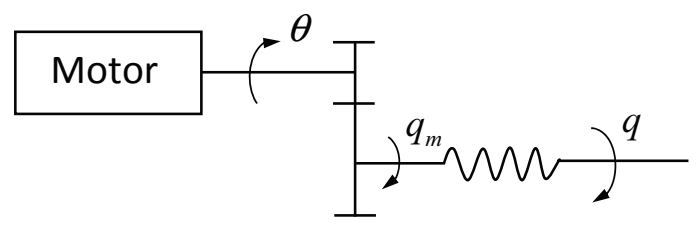

FIGURE 2. Flexible gearbox model

According to [6], a flexible joint robot can be modeled as follows:

$$
\begin{aligned}
D(q) \ddot{q} & =K\left(q_{m}-q\right)-H(q, \dot{q})-f_{q} \dot{q}-J^{T}(q) F \\
J_{m} \ddot{\theta} & =\Gamma_{m}-N_{v} \Gamma-f_{m} \dot{\theta}
\end{aligned}
$$

where $J^{T}(q)$ is the Jacobian matrix of the tool axis position, $F$ represents the effort applied by robot on external process, $\Gamma_{m}$ is the vector of motor torques, $\theta$ represents rotor positions and $q_{m}$ is defined as the positions after the gear reduction, i.e. $q_{m}=N_{v} \theta$, $N_{v}=\operatorname{diag}\left[1 / N_{1}, 1 / N_{2}\right], D(q)$ is the symmetric, uniformly positive definite and bounded inertia matrix. $H(q, \dot{q})$ represents the contribution due to centrifugal, Coriolis and gravitational forces, $f_{q}, f_{m}$ and $J_{m}$ are diagonal matrices with $f_{q}=\operatorname{diag}\left[f_{q 1}, f_{q 2}\right]$, $f_{m}=\operatorname{diag}\left[f_{m 1}, f_{m 2}\right]$ and $J_{m}=\operatorname{diag}\left[J_{m 1}, J_{m 2}\right]$.

It is supposed that the links are rigid and the flexibilities are only localized at the reduction gears and are represented by a stiffness $K=\operatorname{diag}\left[K_{1}, K_{2}\right]$. Therefore, the torque due to the flexibility can be expressed:

$$
\Gamma=K\left(N_{v} \theta-q\right)
$$

\section{B. Modeling of machining process}

The machining process concerned in this part is called a contour milling of composite materials, Dumas discussed this operation in her thesis [17]. The piece is machined within one pass which means that the end of the tool is out of material and the helicoidal angle of the tooth is small, so the axial force $F_{z}$ can be considered as null. The model of cutting force developed by Tlusty and Macneil [18] can be applied in this case:

There are three assumptions:

1. The tangential cutting force $F_{t}$ due to the passage of one tooth is proportional to the cut section:

$$
F_{t}=K_{t} h a_{p}
$$

where $h$ is the thickness of the chip in mm, depth of cut $a_{p}$ in mm and the specific cutting force $K_{t}$ expressed in $\mathrm{N} \mathrm{mm}^{-2}$. The cut surface is equal to $h a_{p}$.

2. The radial cutting force $F_{r}$ due to the passage of one tooth is proportional to the tangential cutting force.

$$
F_{r}=K_{r}\left\|F_{t}\right\|
$$

where $K_{r}$ is a dimensionless coefficient of proportionality essentially depends of the friction effect on the tool.

3. The chip thickness (see Figure 3) can be expressed as follow:

$$
h(\varphi)=f_{z} \sin (\varphi)
$$

with $\varphi$, the angle between the tooth and the normal of the advance direction (between $F_{r}$ and $F_{y}$ ), then :

$$
\delta F_{t}=K_{t} a_{p} f_{z} \sin (\varphi) d \varphi
$$

Because the rotation speed of the tool is high, the harmonics of the force spectrum acted on the robot has little influence. Therefore, the effort $F_{t}$ and $F_{r}$ is calculated as the average effort of each period of rotation. The projection of the radial and tangential forces in the $(x, y)$ frame gives the following equations [17]:

$$
\left\{\begin{array}{l}
F_{x}=\frac{2}{\pi} \int_{\varphi_{s}}^{\varphi_{e}}\left[\left\|\delta F_{t}\right\| \cos (\varphi)+\left\|\delta F_{r}\right\| \sin (\varphi)\right] d \varphi \\
F_{y}=\frac{2}{\pi} \int_{\varphi_{s}}^{\varphi_{e}}\left[-\left\|\delta F_{t}\right\| \sin (\varphi)+\left\|\delta F_{r}\right\| \cos (\varphi)\right] d \varphi
\end{array}\right.
$$

Figure 3 shows the geometric model of clipping and defines the angles $\varphi_{e}$ and $\varphi_{s} . x_{m}$ and $y_{m}$ are denoted as the position of the piece edge, and $\left(x_{2}, y_{2}\right)$ is the axis position of the rotation axis of the tool.

The machining process can be divided into 3 phases:

Phase 1: Relative tool position to the piece with $0<\left(x_{m}-x_{2}\right)$ $\leq R t$ and $\left(x_{m}-x_{2}\right)^{2}+\left(y_{m}-y_{2}\right)^{2}>R_{t}^{2}$ :

$$
\begin{aligned}
& \varphi_{e}=\frac{\pi}{2}-\cos ^{-1}\left[\frac{x_{m}-x_{2}}{R_{t}}\right] \\
& \varphi_{s}=\frac{\pi}{2}+\cos ^{-1}\left[\frac{x_{m}-x_{2}}{R_{t}}\right]
\end{aligned}
$$

Phase 2: Relative tool position to the piece with $\left(x_{m}-x_{2}\right)^{2}+$ $\left(y_{m}-y_{2}\right)^{2} \leq R_{t}^{2}$ and $\left(x_{m}-x_{2}\right)>0$ : 


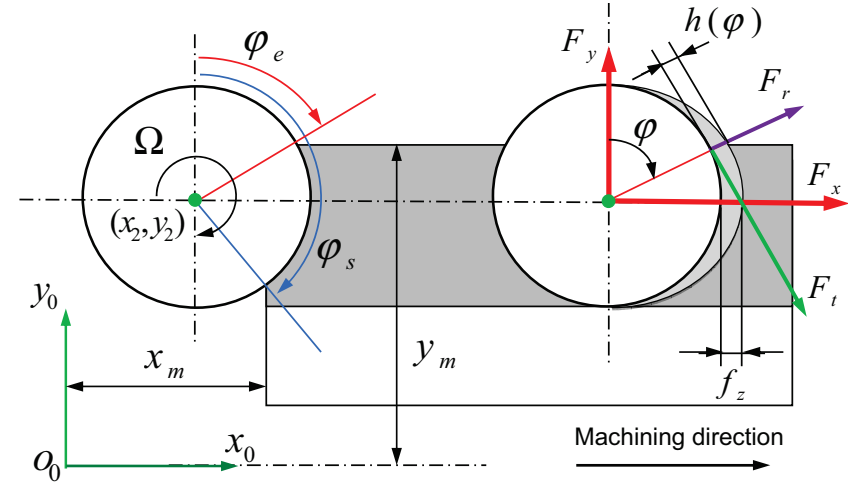

FIGURE 3. Geometric position of the tool during machining process.

$$
\begin{aligned}
& \varphi_{e}=\frac{\pi}{2}-\sin ^{-1}\left[\frac{y_{m}-y_{2}}{R_{t}}\right] \\
& \varphi_{s}=\pi-\sin ^{-1}\left[\frac{x_{m}-x_{2}}{R_{t}}\right]
\end{aligned}
$$

The efforts during phase 1 and phase 2 can be written as follows:

$$
\begin{aligned}
F_{x}= & \frac{K_{t} a_{p} f_{z}}{2 \pi}\left[-\cos \left(2 \varphi_{s}\right)+2 K_{r} \varphi_{s}-K_{r} \sin \left(2 \varphi_{s}\right)\right. \\
& \left.+\cos \left(2 \varphi_{e}\right)-2 K_{r} \varphi_{e}+K_{r} \sin \left(2 \varphi_{e}\right)\right] \\
F_{y}= & \frac{K_{t} a_{p} f_{z}}{2 \pi}\left[\sin \left(2 \varphi_{s}\right)-2 \varphi_{s}-K_{r} \cos \left(2 \varphi_{s}\right)-\sin \left(2 \varphi_{e}\right)\right. \\
& \left.+2 \varphi_{e}+K_{r} \cos \left(2 \varphi_{e}\right)\right]
\end{aligned}
$$

Phase 3: Relative tool position to the piece with $\left(x_{m}-x_{2}\right)$ $<0$, supposing that displacement on direction $y$ is small enough that the angle $\varphi_{s}$ can be considered as constant during the process:

$$
\begin{aligned}
& \varphi_{e}=\pi / 2-\sin ^{-1}\left[\frac{y_{m}-y}{R_{t}}\right] \\
& \varphi_{s}=\pi
\end{aligned}
$$

$$
\begin{aligned}
& F_{x}=\frac{K_{t} a_{p} f_{z}}{2 \pi}\left[2 K_{r}\left(\pi-\varphi_{e}\right)+\cos \left(2 \varphi_{e}\right)-1+K_{r} \sin \left(2 \varphi_{e}\right)\right] \\
& F_{y}=\frac{K_{t} a_{p} f_{z}}{2 \pi}\left[2\left(\varphi_{e}-\pi\right)-\sin \left(2 \varphi_{e}\right)+K_{r} \cos \left(2 \varphi_{e}\right)-K_{r}\right]
\end{aligned}
$$

This cutting force model can simulate the change of the effort during the operation. Note that the parameters $K_{r}$ and $K_{t}$ need to be identified from the measurements of the average force obtained during a machining operation.

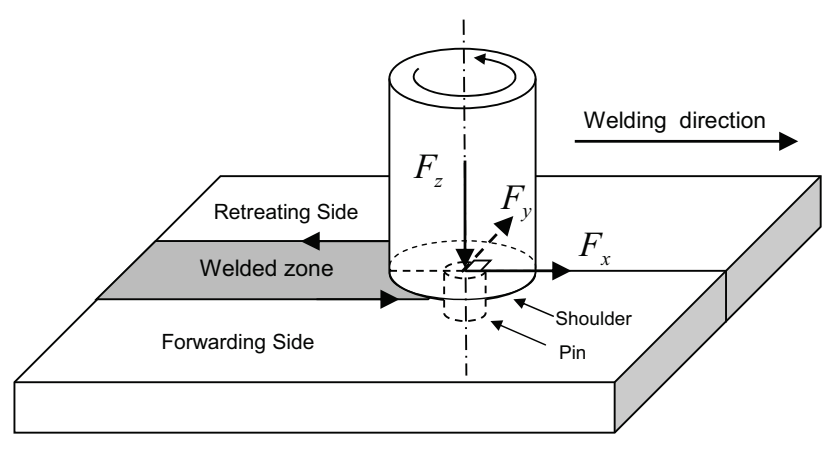

FIGURE 4. Efforts on the tool during the FSW operation

\section{Modeling of FSW process}

The advantage of FSW is to avoid the problems met in classical welding by melting the metals. For this reason, FSW process has been implemented, primarily in the transportation industries that use aluminum to reduce the weight of mechanical structures [2].

This process can be divided into three phases: diving, welding and removing the tool. This paper focus on the welding phase which is similar to our machining process. To simplify the process, it is supposed that the tool is always perpendicular to the plan during the operation. In order to improve the tracking performance, the axial effort $F_{z}$, path effort $F_{x}$ and normal effort $F_{y}$ (see Figure 4) are needed. Control of the external weld force is desirable to improve the weld quality. However, not all the external forces are measured in industrial applications due to the high price of these force sensors and some of them are not measurable.

The axial force in FSW process is the pressure produced by the pin and shoulder of the tool. The path force is the force imposed on the tool along the welding direction. The normal force is the force imposed on the tool in the plane of the part and perpendicular to the path direction, this force is typically directed from the weld retreating side to the weld advancing side and is caused by the unbalance of the material flow on the two sides.

Based on static model of [19], the expression of efforts can be written as follows:

$$
\begin{aligned}
& F_{z}=K_{z} d^{\alpha_{z}} v^{\beta_{z}} \Omega^{\lambda_{z}} \\
& F_{x}=K_{x} v^{\beta_{x}} \Omega^{\lambda_{x}} \\
& F_{y}=K_{y} d^{\alpha_{y}} v^{\beta_{y}} \Omega^{\lambda_{y}}
\end{aligned}
$$

where $\Omega$ is the spindle rotation speed, $v$ is the travel speed along the path, $d$ is the plunge depth, and the unknown parameters $K_{i}, \alpha_{i}, \beta_{i}, \lambda_{i} ; i \in[x, y, z]$ can be estimated using the Least Squares method. 


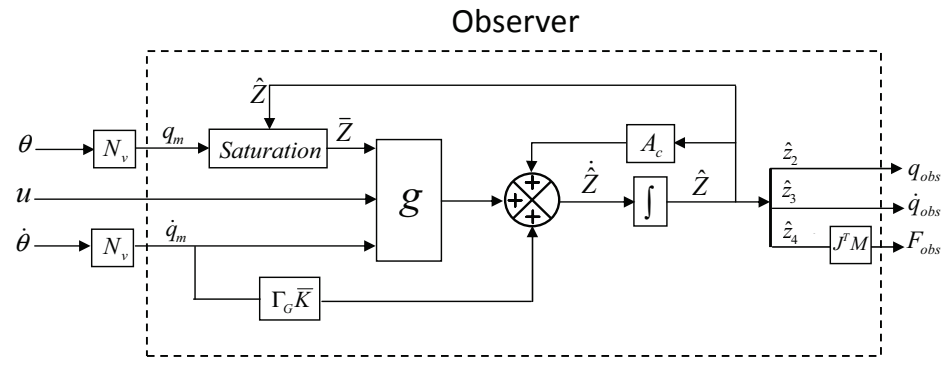

FIGURE 5. Diagram of the observer

\section{OBSERVER DESIGN}

Disturbance observer technique is widely used in control for improving disturbance rejection and robust performance [20]. The unknown input observer (UIO) method is one of the most well known approach to estimate states [21]. Hereafter, assuming that the articular position and velocity of motor axis and the effort $F_{z}$ are measured by sensors. A reduced order high-gain observer is then proposed to reconstruct the articular position and velocity of links and the process efforts $F_{x}$ and $F_{y}$. The new observer proposed in this paper, is based on a nonlinear observer introduced in [9], which reconstructs the articular position and velocity of links thanks to the measures of the position and velocity of motor axis. Observer described in [9] is then modified in order to get also an estimation of efforts by adding more state variables function of this force.

If the state variables $x_{i}$ are defined as: $x_{1}=q=\left[\begin{array}{ll}q_{1} & q_{2}\end{array}\right]^{T}$, $x_{2}=\dot{q}=\left[\begin{array}{ll}\dot{q}_{1} & \dot{q}_{2}\end{array}\right]^{T}, x_{3}=q_{m}=\left[\begin{array}{ll}q_{m 1} & q_{m 2}\end{array}\right]^{T}, x_{4}=\dot{q}_{m}=\left[\begin{array}{ll}\dot{q}_{m 1} & \dot{q}_{m 2}\end{array}\right]^{T}$, $q_{m}=N_{v} \theta$ and the gear factor $N=\operatorname{diag}\left[N_{1}, N_{2}\right]$ the following state space model can be obtained:

$$
\left\{\begin{array}{l}
\dot{x}_{1}=x_{2} \\
\dot{x}_{2}=\ddot{q}=D(q)^{-1}\left[K\left(q_{m}-q\right)-H(q, \dot{q})-f_{q} \dot{q}-J^{T}(q) F\right] \\
\dot{x}_{3}=x_{4} \\
\dot{x}_{4}=\ddot{q}_{m}=\left(J_{m} N^{2}\right)^{-1}\left[N \Gamma_{m}-\Gamma-\left(f_{m} N^{2}\right) \dot{q}_{m}\right]
\end{array}\right.
$$

The measured variables are now denoted $y$ and the following change of coordinates is considered:

$$
\left\{\begin{array}{l}
z_{1}=\left[\left(J_{m} N^{2}\right)^{-1} K\right]^{-1} x_{4}=K^{-1}\left(J_{m} N^{2}\right) x_{4} \\
z_{2}=x_{1}=q \\
z_{3}=x_{2}=\dot{q} \\
z_{4}=J^{T}\left(z_{2}\right) F \\
y_{1}=x_{3}=q_{m} \\
y_{2}=x_{4}=\dot{q}_{m}
\end{array}\right.
$$

Moreover, if $u=N \Gamma_{m}$ and $f_{m} N^{2}=F_{m}$, then:

$$
\left\{\begin{array}{l}
\dot{z}_{1}=z_{2}+K^{-1}\left(J_{m} N^{2}\right) \dot{x}_{4}=K^{-1} u-y_{1}-K^{-1} F_{m} y_{2} \\
\dot{z}_{2}=z_{3} \\
\dot{z}_{3}=\ddot{q}=z_{4}+\psi\left(z_{2}, z_{3}, y_{1}, F\right) \\
\dot{z}_{4}=\frac{d}{d t}\left[J^{T}\left(z_{2}\right) F\right]
\end{array}\right.
$$

where $\psi$ is equal to:

$$
\psi=D\left(z_{2}\right)^{-1}\left[K\left(y_{1}-z_{2}\right)-H\left(z_{2}, z_{3}\right)-f_{q} z_{3}-J^{T}\left(z_{2}\right) F\right]-z_{4}
$$

If $A$ and $C$ are defined as following ( $I$ is the 2 order identity matrix and 0 is the $2 \times 2$ zero matrix ):

$$
A=\left(\begin{array}{cccc}
0 & I & 0 & 0 \\
0 & 0 & I & 0 \\
0 & 0 & 0 & I \\
0 & 0 & 0 & 0
\end{array}\right) \text { and } C=\left(\begin{array}{llll}
I & 0 & 0 & 0
\end{array}\right)
$$

then:

$$
\dot{z}=A z+g(z, y, u)+d(z, F, \dot{F})
$$

with

$$
g=\left\{\begin{array}{l}
K^{-1} u-y_{1}-K^{-1} F_{m} y_{2} \\
0 \\
\psi\left(z_{2}, z_{3}, y_{1}, F\right) \\
0
\end{array}\right.
$$

and $d(z, F, \dot{F})=\left[\begin{array}{llll}0 & 0 & 0 & \frac{d}{d t}\left(J^{T}\left(z_{2}\right) F\right)\end{array}\right]^{T}$.

Define now the following matrix of high gains, with $G$ a constant $\geq 1$ :

$$
\Gamma_{G}=\left(\begin{array}{cccc}
G I & 0 & 0 & 0 \\
0 & G^{2} I & 0 & 0 \\
0 & 0 & G^{3} I & 0 \\
0 & 0 & 0 & G^{4} I
\end{array}\right)
$$

and matrix $L$ such as $(A-L C)$ has all its eigenvalues in the left half of the complex plan, then the following new observer is proposed:

$$
\dot{\hat{z}}=\left(A-\Gamma_{G} L C\right) \hat{z}+g(\bar{z}, y, u)+\Gamma_{G} \bar{K} y_{2}
$$

where $\bar{K}=L K^{-1}\left(J_{m} N^{2}\right)$ and

$$
\left\{\begin{array}{l}
\bar{z}_{2}=y_{1}-\frac{y_{1}-\hat{z}_{2}}{\left\|y_{1}-\hat{z}_{2}\right\|} N_{s} \operatorname{sat}\left(\frac{\left\|y_{1}-\hat{z}_{2}\right\|}{N_{s}}\right) \\
\bar{z}_{3}=\frac{\hat{z}_{3}}{\left\|\hat{z}_{3}\right\|} M_{s} \operatorname{sat}\left(\frac{\left\|\hat{z}_{3}\right\|}{M_{s}}\right) \\
\bar{z}_{4}=\frac{\hat{z}_{4}}{\left\|\hat{z}_{4}\right\|} F_{s} \operatorname{sat}\left(\frac{\left\|z_{4}\right\|}{F_{s}}\right)
\end{array}\right.
$$

with sat(.) is the saturation function:

$$
\operatorname{sat}(x)= \begin{cases}x & \text { if }|x| \leq 1 \\ 1 & \text { if }|x|>1\end{cases}
$$

and $M_{s}, N_{s}, F_{M}, F_{d}, J_{M}$ and $F_{s}$ are known positive physical constant bounds:

$$
\left\{\begin{array}{l}
\left\|x_{2}\right\|<M_{s} \\
\left\|x_{1}-x_{3}\right\|<N_{s} \\
\|F\|<F_{M} \\
\|\dot{F}\|<F_{d} \\
\left\|J^{T}\left(z_{2}\right)\right\|<J_{M} \\
F_{s}=J_{M} F_{M}
\end{array}\right.
$$


Figure 5 shows the diagram of the proposed observer where $A_{c}=$ $A-\Gamma_{G} L C$. For only one axis, $L=\left[L_{1} L_{2} L_{3} L_{4}\right]^{T}$ and:

$$
\operatorname{det}[\lambda I-(A-L C)]=\lambda^{4}+L_{1} \lambda^{3}+L_{2} \lambda^{2}+L_{3} \lambda+L_{4}
$$

where $\lambda$ is an eigenvalue of matrix $A-L C$. A possible choice for $L$ is then: $L_{1}=4 a, L_{2}=6 a^{2}, L_{3}=4 a^{3}$ and $L_{4}=a^{4}$. In this case, matrix $A-L C$ has four stable eigenvalues in $\lambda=-a$, where $a$ is a positive real fixing the dynamics of the proposed observer.

The estimation error $e=z-\hat{z}$ satisfies the following differential equation:

$$
\dot{e}=A_{c} e+g(z, y, u)-g(\bar{z}, y, u)+d(z, F, \dot{F})
$$

Because of the form of disturbance $d(z, F, \dot{F})$ the following stability theorem can be proven for the proposed observer:

Theorem 1: There exists a constant $G^{0}$ such that error $e(t)$ is bounded for any gain $G>G^{0}$.

The proof is given in Appendix A.

This observer is compatible with the FSW and machining processes mentioned before.

\section{OBSERVER PERFORMANCE AND ROBUSTNESS ANALYSIS}

A simulation is carried out with Matlab/Simulink to analyze the performance and robustness of the observer. The essential parameters are taken from a robot IBM7545 as shown in Table 1. The results estimated by observer are compared with the results of the system. The Figure 6 shows the block diagram of industrial control system dividing in two parts: the first part is an internal loop with a PI controller for the velocity of the rotor and the second part is an external loop with a PID controller for the position of the motor [22]. The flexibility and external force are also added in this control system as showed in Figure 6. The controllers of IBM robot are designed as independent axis. The controllers are solved axis by axis, e.g. for axis 1: PI and PID are tuned in order to fix the bandwidth of velocity loop to $\omega_{01}=1800 \mathrm{rad} / \mathrm{s}$ and the bandwidth of position loop to $\omega_{1}=600 \mathrm{rad} / \mathrm{s}$, the corresponding tuning rules can be found in [22], and are remained hereafter. The gains of PI controller:

$$
\left\{\begin{array}{l}
K_{i 1}=\omega_{01}^{2} J_{m 1} / K_{e 1} \\
K_{p 1}=\left(2 \xi \omega_{01} J_{m 1}-f_{m 1}\right) / K_{e 1}
\end{array}\right.
$$

and the gains of PID controller:

$$
\left\{\begin{array}{l}
K_{i p 1}=\frac{N_{1} \omega_{1}^{4}}{\omega_{01}^{2}} \\
K_{d p 1}=\frac{6 \omega_{1}^{2}}{\omega_{01}^{2}}-1 \\
K_{p p 1}=\frac{4 \omega_{1}^{3}}{\omega_{01}^{2}}
\end{array}\right.
$$

the numerical values are presented as follows:

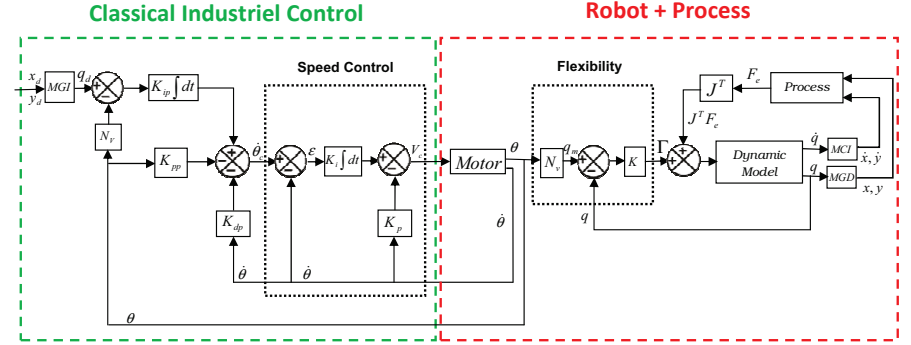

FIGURE 6. Principal block diagram of an industrial robot control

$$
\begin{aligned}
& K_{i}=\operatorname{diag}\left[4.4210^{3}, 3.0010^{3}\right] \\
& K_{p}=\operatorname{diag}[3.93,2.67] \\
& K_{i p}=\operatorname{diag}\left[6.2810^{6}, 3.210^{6}\right] \\
& K_{p p}=\operatorname{diag}\left[2.6710^{2}, 2.6710^{2}\right] \\
& K_{d p}=\operatorname{diag}[-0.33,-0.33]
\end{aligned}
$$

For observer gains, $a=2000$ and $G=1$ are sufficient to guarantee the stability of proposed observer (31), (32). Moreover, a noise of quantization is added to the measures of the proposed observer. The quantum size $h=2 \pi / 4096$ is implemented since sampled data are stored as 12 integers. The workpiece was milled along about $500 \mathrm{~mm}$ linear path with the machining conditions of the simulation presented in Table 2.

TABLE 2. Machining conditions of the simulation.

\begin{tabular}{lll}
\hline Name & Value & Unit \\
\hline material & Aluminium alloy & \\
tool diameter & 20 & $\mathrm{~mm}$ \\
cut depth $\left(a_{p}\right)$ & 2 & $\mathrm{~mm}$ \\
cut width $\left(a_{e}\right)$ & 5 & $\mathrm{~mm}$ \\
specific cutting coefficient $\left(K_{t}\right)$ & 1.9 & $\mathrm{GPa}$ \\
forward speed $(\dot{y})$ & 0.06 & $\mathrm{~m} / \mathrm{s}$ \\
rotation speed $\left(N_{r}\right)$ & 18000 & $\mathrm{rpm}$ \\
number of teeth & 4 & \\
\hline
\end{tabular}

The machining force in direction $y$ is about 60 N. Simulation results are presented in the Figures 7 to 17, where it could be seen that the observer can overcome process disturbances and model errors. Figures 7 and 8 present the tracking performance of the system, e.g. for a given desired trajectory in Figure 7, the tracking error is about $10^{-4} \mathrm{rad}$ in the machining direction and $10^{-6} \mathrm{rad}$ in its normal direction. Then, Figures 9 to 14 present the evaluations of $q, \dot{q}$ and $F$ during the process and the estimate error of our observer. Finally, Figures 15 to 17 demonstrate the 
obtained errors with adding quantization on the measured position $\theta$.

The results show that observer is fast enough to follow the system and has a good accuracy and sensibility. It can realize not only the state reconstruction but also the effort estimation. Even with a big disturbance at the beginning, when the tool is entering the material, an precision of $10^{-7} \mathrm{rad}$ for the joint position, $10^{-4} \mathrm{rad} / \mathrm{s}$ for the joint velocity and $1 N$ for the effort is obtained. Even with a noise of quantization, the results still show good performances with errors of about $10^{-5} \mathrm{rad}, 10^{-2} \mathrm{rad} / \mathrm{s}$ and $5 \mathrm{~N}$.

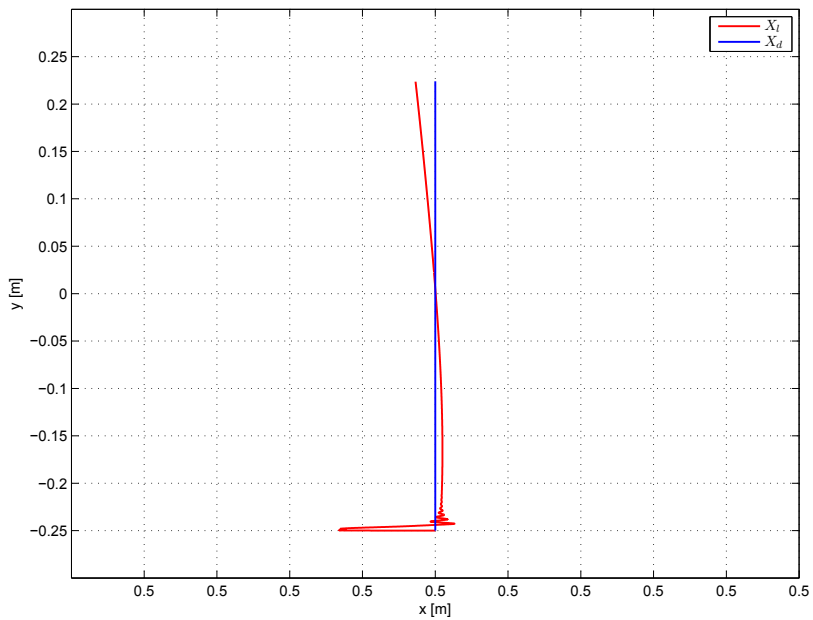

FIGURE 7. Desired trajectory $X_{d}$ and real trajectory $X_{l}[\mathrm{~m}]$

\section{CONCLUSION}

In this paper, two models of machining and FSW are presented and a non-linear disturbance observer is proposed for the control of flexible joints industrial robots. A simulation has also been carried out with Matlab/Simulink for a machining process which demonstrates that the proposed observer is fast enough to follow the system and shows a good accuracy and sensibility. Even with a noise of quantification, our observer still provides satisfactory results in both state and force estimations.

This method can also be applied to FSW process. In any case, the robot parameters are needed to implement the proposed observer. For instance, in our laboratory, numerous experiments have been carrying out to identify all the parameters of a KUKA KR500-2MT in order to weld pieces by using FSW process, meanwhile, the same characterization on another robot KUKA KR270 used for machining of composites materials has been carrying out by some partners of COROUSSO project [17].
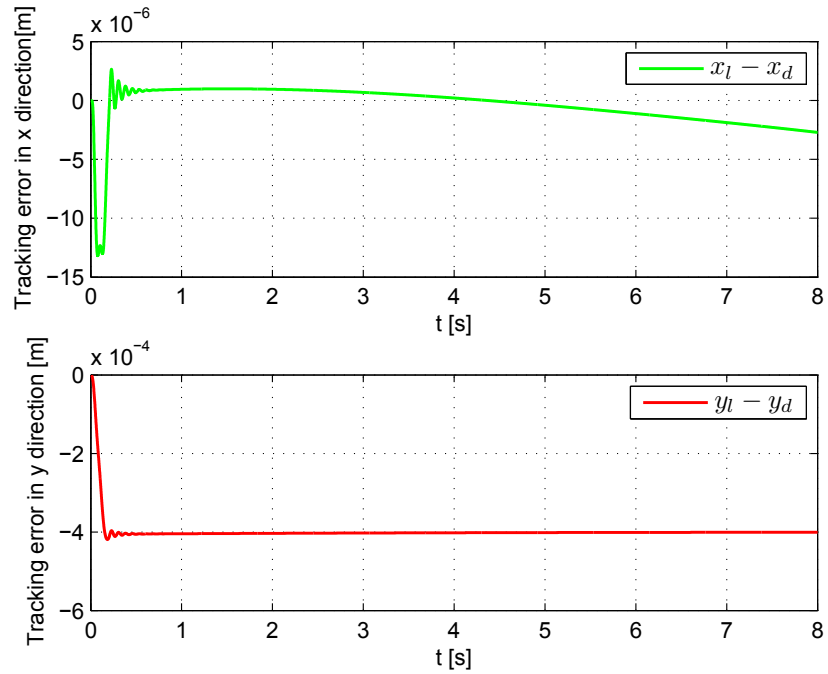

FIGURE 8. Error of tracking trajectory [m]

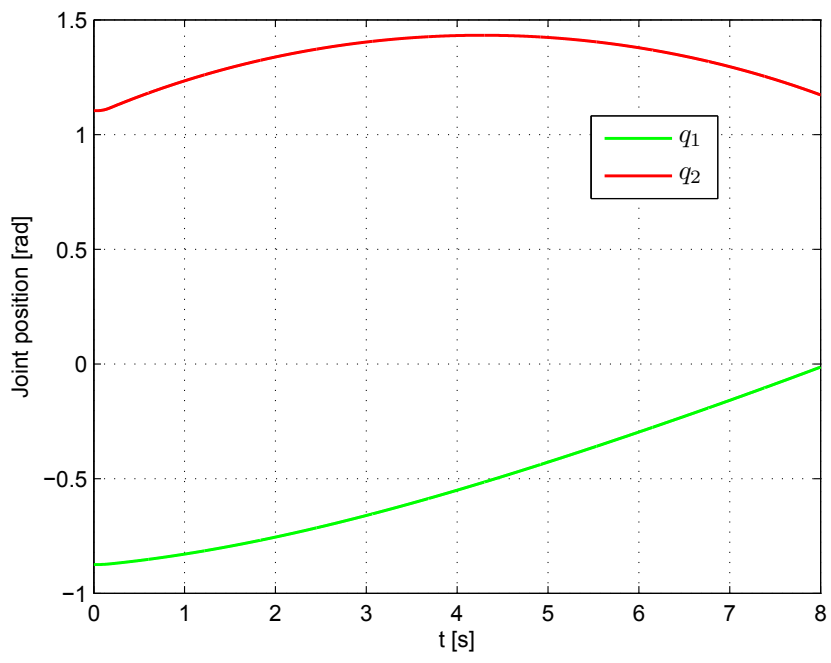

FIGURE 9. Joint position [rad]

Moreover, using the measured state of motors and the estimated state of robot links in the control of flexible robots can lead to more stable and robust feedback control as shown in $[6,22]$.

\section{ACKNOWLEDGMENT}

This research is sponsored by the French National Agency of Research as a part of the program ANR-ARPEGE, project ANR2010-SEGI-003-01-COROUSSO. 

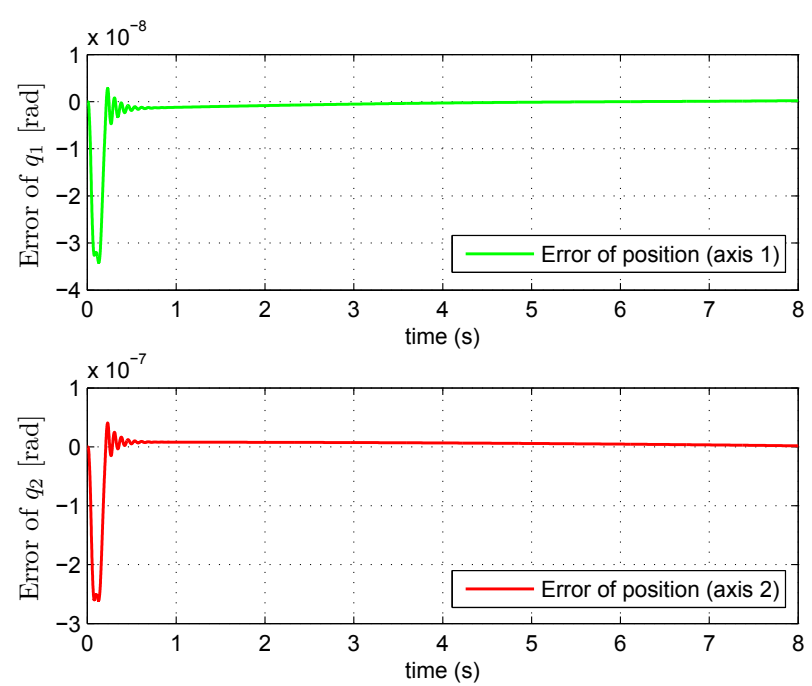

FIGURE 10. Observer error of angular position [rad]

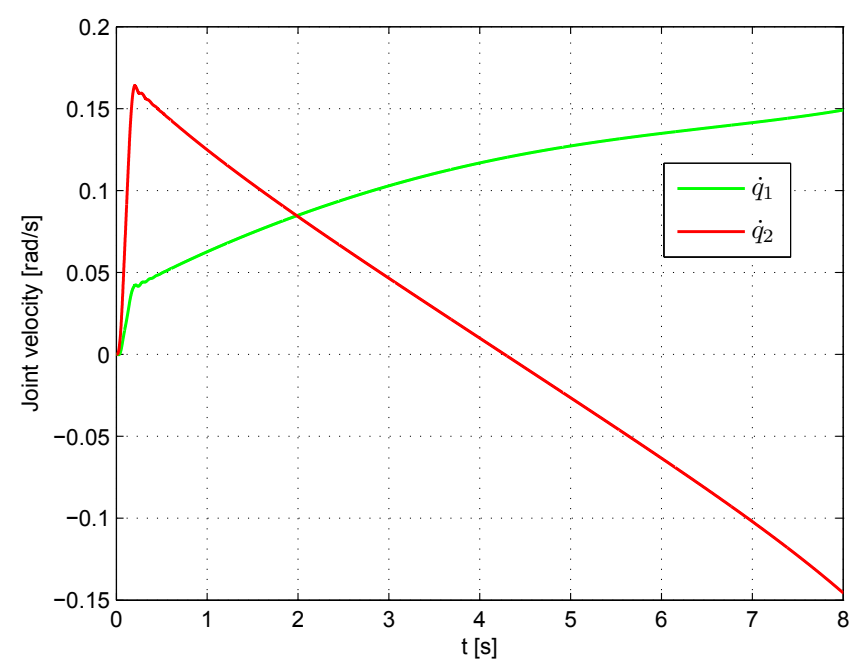

FIGURE 11. Joint velocity $[\mathrm{rad} / \mathrm{s}]$

\section{Appendix A: Proof of theorem 1}

Proof of theorem: Consider the linear change of coordinates $\eta=\Gamma_{G}^{-1} e$, then differential equation (36) becomes :

$$
\dot{\eta}=G(A-L C) \eta+\Gamma_{G}^{-1}(g(z, y, u)-g(\bar{z}, y, u))+\Gamma_{G}^{-1} d(z, F, \dot{F})
$$

For this new system, define Lyapunov function $V(\eta)=\eta^{T} P \eta$ where $P$ is the positive definite solution of Lyapunov matrix equation:

$$
(A-L C)^{T} P+P(A-L C)=-I
$$
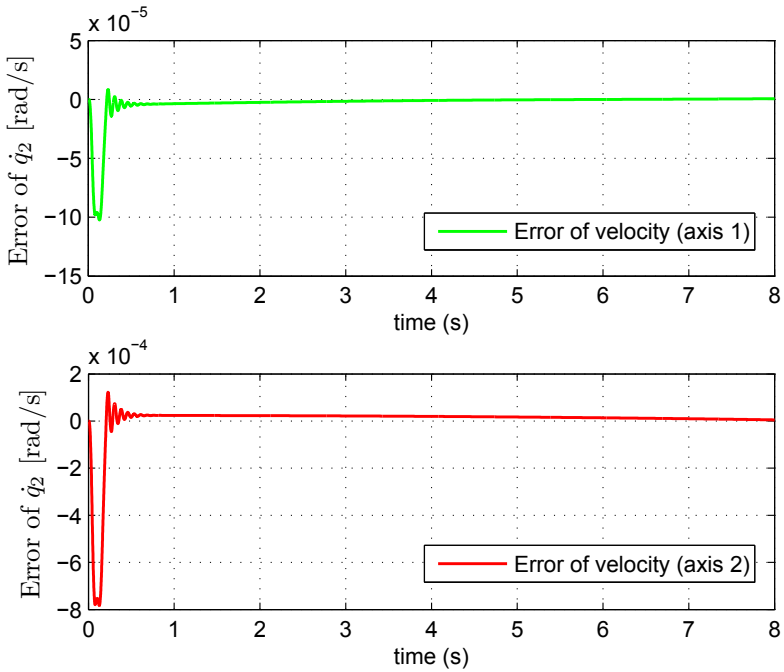

FIGURE 12. Observer error of angular velocity [ $\mathrm{rad} / \mathrm{s}]$

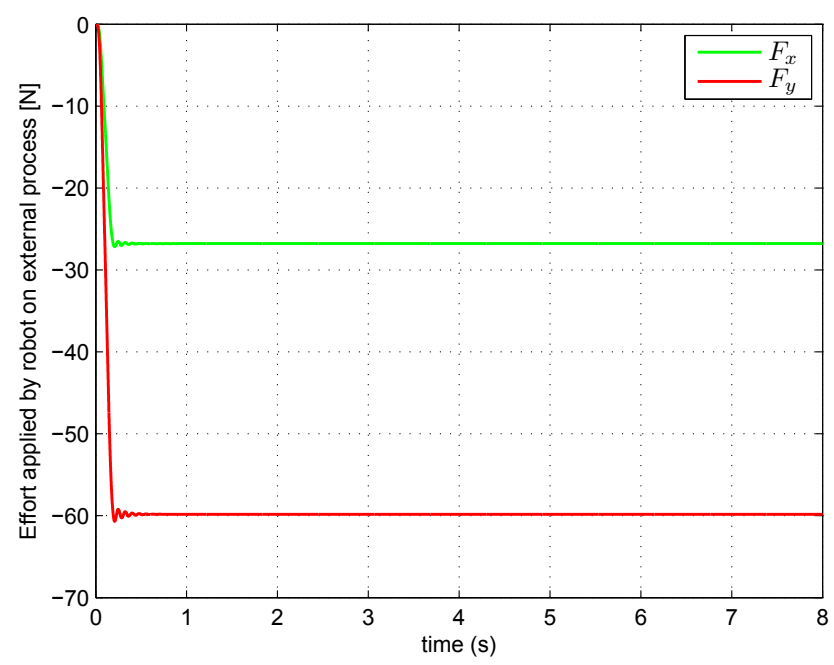

FIGURE 13. Effort applied by robot on external process [N]

Taking the derivative of $V(\eta)$, one can obtain:

$\dot{V} \leq-G\|\eta\|^{2}+2\|\eta\|\|P\|\left(G^{-3} \| \psi(z)-\psi\left(\bar{z}\left\|+G^{-4}\right\| d(z, F, \dot{F} \|)\right.\right.$

From relation (32) and (34) by using [9], the saturation condition can be written:

$$
\begin{aligned}
\left\|z_{2}-\bar{z}_{2}\right\| & \leq\left\|z_{2}-\hat{z}_{2}\right\| \\
\left\|z_{3}-\bar{z}_{3}\right\| & \leq\left\|z_{3}-\hat{z}_{3}\right\|
\end{aligned}
$$

Moreover, as $D^{-1}, H, J^{T}, z_{3}, \bar{z}_{3}, F, z_{4}$ and $\bar{z}_{4}$ are bounded then: 

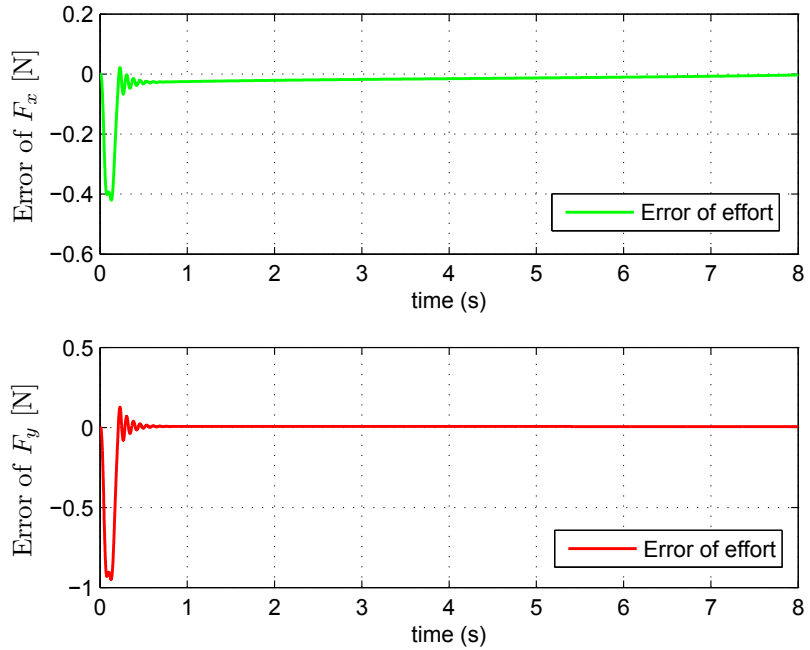

FIGURE 14. Observer error of external force [Nm]
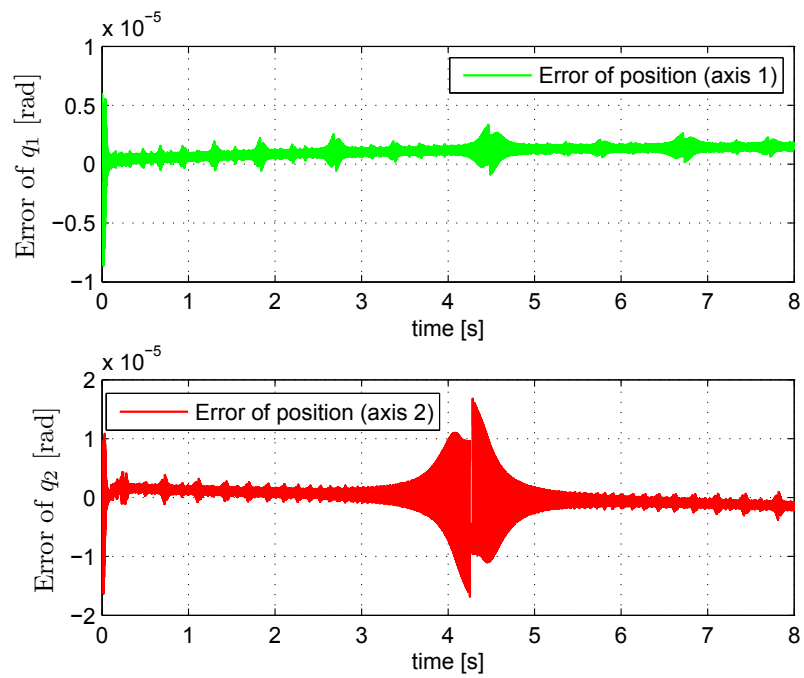

FIGURE 15. Observer error of angular position with quantization noise [rad]

$$
\|\psi(z)-\psi(\bar{z})\| \leq \alpha_{2}\left\|z_{2}-\hat{z}_{2}\right\|+\alpha_{3}\left\|z_{3}-\hat{z}_{3}\right\|+\left\|z_{4}-\bar{z}_{4}\right\|
$$

where $\alpha_{2}$ and $\alpha_{3}$ are positive constants. As:

$$
\left\|z_{4}-\bar{z}_{4}\right\| \leq\left\|z_{4}\right\|+\left\|\bar{z}_{4}\right\| \leq 2 F_{S}
$$

and $\eta=\Gamma_{G}^{-1} e$ then the following inequalities hold:

$$
\|\psi(z)-\psi(\bar{z})\| \leq \alpha_{2} G^{2}\left\|\eta_{2}\right\|+\alpha_{3} G^{3}\left\|\eta_{3}\right\|+2 F_{s}
$$
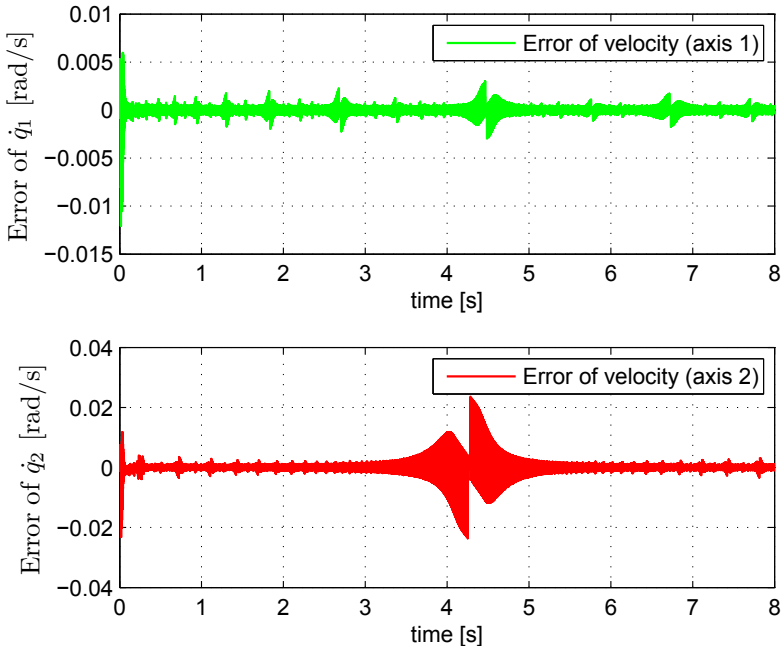

FIGURE 16. Observer error of angular velocity with quantization noise $[\mathrm{rad} / \mathrm{s}]$
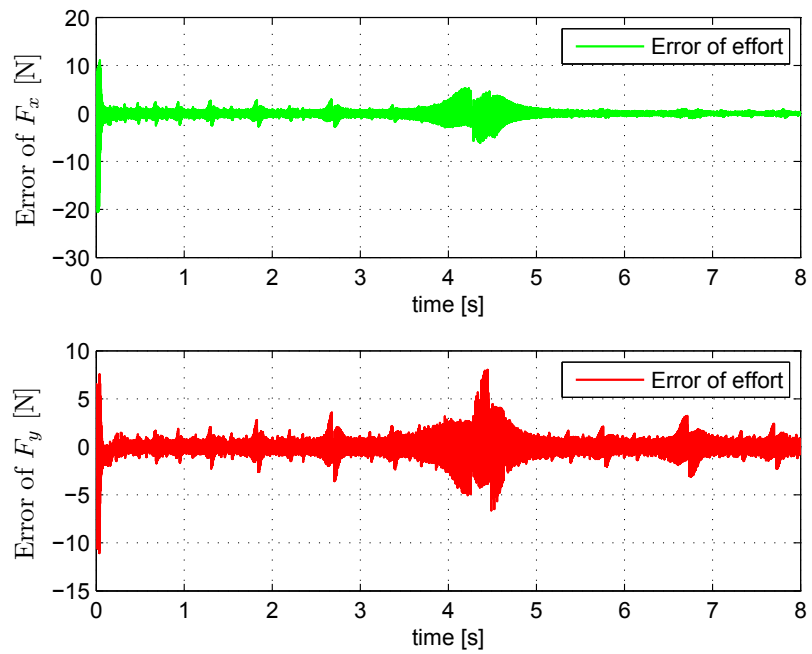

FIGURE 17. External force observer error with quantization noise $[\mathrm{N}]$

$$
\begin{aligned}
& \leq 2 G^{3} \sup \left(\alpha_{2} G^{-1}, \alpha_{3}\right)\|\eta\|+2 F_{s} \\
& \leq 2 G^{3} \alpha_{m}\|\eta\|+2 F_{s}
\end{aligned}
$$

with $\alpha_{m}=\sup \left(\alpha_{2}, \alpha_{3}\right)$ as $G \geq 1$. Now:

$$
\|d(z, F, \dot{F})\|=\left\|\frac{d}{d t}\left(J^{T}\left(z_{2}\right) F\right)\right\|
$$




$$
=\left\|\frac{\partial}{\partial z_{2}}\left(J^{T}\left(z_{2}\right)\right) \dot{z}_{2}+J^{T}\left(z_{2}\right) \dot{F}\right\|
$$

as $J^{T}\left(z_{2}\right)$ and $\frac{\partial}{\partial z_{2}}\left(J^{T}\left(z_{2}\right)\right)$ depend on $z_{2}$ only through sine and cosine functions and $\dot{F}$ and $\dot{z}_{2}$ are bounded, one can find a positive bound $d_{m}$ for $\|d(z, F, \dot{F})\|$ :

$$
\|d(z, F, \dot{F})\| \leq d_{m}
$$

Now reporting (46) and (47) in (41) provides:

$$
\dot{V} \leq\left(-G+G_{0}\right)\|\eta\|^{2}+2\|\eta\|\|P\|\left(2 G^{-3} F_{s}+G^{-4} d_{m}\right)
$$

where $G_{0}=4\|P\| \alpha_{m}$.

If $G>G_{0}, \dot{V}<0$ for $\|\eta\|>r(G)$ where:

$$
r(G)=\frac{2\|P\|\left(2 G^{-3} F_{s}+G^{-4} d_{m}\right)}{G-G_{0}}
$$

what means after a finite time $\tau,\|\eta\| \leq r(G)$ and:

$$
\|e\| \leq G^{4}\|\eta\| \leq \frac{2\|P\|\left(2 F_{s}+G^{-1} d_{m}\right)}{1-G^{-1} G_{0}}
$$

which proves that $e(t)$ is bounded if $G>G_{0}$.

\section{REFERENCES}

[1] Zimmer, S., 2009. "Contribution à l'industrialisation du soudage par friction malaxage". Phd thesis, Ecole Nationale Supérieure d'Arts et Métiers, Metz, France.

[2] Bres, A., Monsarrat, B., Dubourg, L., Birglen, L., Perron, C., Jahazi, M., and Baron, L., 2010. "Simulation of friction stir welding using industrial robots". Industrial Robot: An International Journal, 37(1), pp. 36-50.

[3] Moberg, S., 2007. "On modeling and control of flexible manipulators". Phd thesis, Linköping University, Linköping, Sweden.

[4] Grotjahn, M., and Heimann, B., 2002. "Model-based feedforward control in industrial robotics". The International Journal of Robotics Research, 21(1), pp. 45-60.

[5] Khalil, W., and Dombre, E., 2004. Modeling, Identification and Control of Robots. Elsevier Ltd, Oxford.

[6] Spong, M., Hutchinson, S., and Vidyasagar, M., 2005. Robot Modeling and Control. John Wiley and Sons, Inc., Berlin Heidelberg.

[7] Siciliano, B.and Khatib, O., 2008. Springer Handbook of Robotics. Springer Verlag, Berlin Heidelberg.

[8] Siciliano, B., Sciavicco, L., Villani, L., and Oriolo, G., 2010. Robotics: Modelling, Planning and Control. Springer Verlag, London.
[9] Jankovic, M., 1995. "Observer based control for elastic joint robots". IEEE Transactions on Robotics and Automation, 11(4), pp. 618-623.

[10] Besançon, G., 2007. Nonlinear Observers and Applications, 1 ed. Springer, Berlin Heidelberg.

[11] Davis, T. A., Shin, Y. C., and Yao, B., 2011. "Observerbased adaptive robust control of friction stir welding axial force". IEEE/ASME Transactions on Mechatronics, 16(6), pp. 1032-1039.

[12] Kravaris, C., Sotiropoulos, V., Georgiou, C., Kazantzis, N., Xiao, M. Q., and Krener, A. J., 2007. "Nonlinear observer design for state and disturbance estimation". Systems Control Letters, 56(11-12), pp. 730-735.

[13] De Luca, A., Schröder, D., and Thümmel, M., 2007. “An acceleration-based state observer for robot manipulators with elastic joints.". In IEEE International Conference on Robotics and Automation, pp. 3817-3823.

[14] Subrahmanya, N., and Shin, Y. C., 2009. "Adaptive divided difference filtering for simultaneous state and parameter estimation". Automatica, 45(7), pp. 1686-1693.

[15] Spurgeon, S. K., 2008. "Sliding mode observers: a survey". International Journal of Systems Science, 39(8), pp. 751764.

[16] Yao, Y. L., and Cheng, W. Y., 1999. "Model-based motion planing for robotic assembly of non-cylindrical parts". The International Journal of Advanced Manufacturing Technology, Springer-Verlag London Ltd, 15, pp. 683-691.

[17] Dumas, C., 2011. "Développement de méthodes robotisées pour le parachèvement de pièces métalliques et composites". Phd thesis, Université de Nantes, Nantes, France.

[18] Tlusty, J., and Macneil, P., 1975. "Dynamics of cutting forces in end milling". Annals of the CIRP, 24(1), pp. 2125.

[19] Zhao, X., Kalya, P., Landers, R. G., and Krishnamurthy, K., 2008. "Design and implementation of a nonlinear axial force controller for friction stir welding processes". Journal of Manufacturing Science and Engineering, Transactions of the ASME, 130(6), pp. 5553-5558.

[20] Park, S. K., and Lee, S. H., 2007. "Disturbance observer based robust control for industrial robots with flexible joints". In International Conference on Control, Automation and Systems 2007, ICCAS '07, pp. $584-589$.

[21] Xiong, Y., and Mehrdad, S., 2003. "Unknown disturbance inputs estimation based on a state functional observer design". Automatica, 39(8), pp. 1389-1398.

[22] Qin, J., Léonard, F., and Abba, G., 2011. "Commande robuste d'un robot d'usinage flexible: analyse de la précision”. In 20ème Congrès Français de Mécanique, CdRom 395.pdf. 